\title{
$\beta$-human chorionic gonadotropin-secreting intracranial germ-cell tumor associated with high testosterone in an adult man: A case report
}

\author{
WEN-PING YANG ${ }^{1}$, HUNG-YU CHIEN ${ }^{1}$ and YI-CHUN LIN ${ }^{2,3}$ \\ ${ }^{1}$ Section of Endocrinology and Metabolism, Department of Medicine, Taipei City Hospital Ren-Ai Branch, Taipei 106; \\ ${ }^{2}$ Section of Endocrinology and Metabolism, Department of Medicine, Taipei Veterans General Hospital, \\ Taipei 112; ${ }^{3}$ Faculty of Medicine, National Yang-Ming University, Taipei 112, Taiwan, R.O.C.
}

Received September 16, 2015; Accepted March 7, 2017

DOI: $10.3892 / \mathrm{ol} .2017 .6213$

\begin{abstract}
A 38-year-old male patient presented with general weakness, polydipsia and a body weight loss of $10 \mathrm{~kg}$ in two years. Hypopituitarism with central hypothyroidism and central adrenal insufficiency were noted at Taipei City Hospital (Taipei, Taiwan). However, hypogonadotropic hypergonadism was also observed. The patient was diagnosed with an intracranial $\beta$-human chorionic gonadotropin $(\beta-\mathrm{hCG})$ secreting germ-cell tumor, and brain magnetic resonance imaging revealed that the tumor involved the pineal gland, stalk, posterior pituitary gland, right basal ganglion, hypothalamus, corpus callosum and posterior hippocampus. The cerebrospinal fluid (CSF) $\beta$-hCG level was 1936 IU/l, while the $\alpha$-fetoprotein (AFP) level was $<0.24 \mathrm{ng} / \mathrm{ml}$. The serum AFP level of the patient was $3.28 \mathrm{ng} / \mathrm{ml}$, and the $\beta$-hCG level was $178 \mathrm{IU} / 1$ with a CSF:serum $\beta$-hCG ratio $>2: 1$. The patient was successfully treated with chemotherapy and radiotherapy, as demonstrated by a marked decrease in size of the tumor and in the serum $\beta$-hCG levels. Intracranial $\beta$-hCG secreting germ-cell tumors are rare in adults and manifest differently compared with patients of early pubertal age. In contrast with the precocious puberty frequently observed in young patients, the diagnosis of adult patients is often delayed and the symptoms are associated with tumor size and location. The present case report described an adult male with an intracranial $\beta$-hCG secreting GCT, demonstrating hypopituitarism and asymptomatic hyperandrogenemia, and reviews and discusses the literature relevant to the case.
\end{abstract}

Correspondence to: Dr Yi-Chun Lin, Section of Endocrinology and Metabolism, Department of Medicine, Taipei Veterans General Hospital, 201 Shih-Pai Road, Taipei 112, Taiwan, R.O.C.

E-mail: f084533@yahoo.com.tw

Key words: intracranial germ-cell tumor, $\beta$-human chorionic gonadotropin, hypogonadotropic hypergonadism

\section{Introduction}

Primary intracranial germ-cell tumors (GCT) are rare tumors. They account for $\sim 0.5-3 \%$ of all pediatric primary central nervous system (CNS) tumors in Western regions, but are observed at higher frequencies among pediatric CNS tumors in Asia, accounting for up to $10 \%$ (1). The incidence in the Far East area of Japan is 0.1-0.17 per 100,000 per year, according to the Brain Tumor Registry of Japan (2), slightly higher than the incidence rate of 0.1 per 100,000 per year in the United States (3). Primary intracranial GCT typically occurs in children or young adults, with the majority of patients (60-70\%) aged under 20 (4). The peak incidence of intracranial germ-cell tumors is in the early pubertal period with a median age of diagnosis at 10-12 years (5). The disease occurs primarily in males, with the ratio of male to female between 2:1 and 3:1 (6). The World Health Organization had classified intracranial germ-cell tumors into three groups as follows: Germinomas, non-germinomatous germ-cell tumors (NGGCTs) and mixed germ-cell tumors (7). The diseases are heterogeneous in terms of histology, tumor characteristics, treatment response and tumor marker secretion. Among NGGCTs, choriocarcinoma secretes $\beta$-human chorionic gonadotropin ( $\beta$-HCG) into the serum and/or the cerebrospinal fluid (CSF), with high levels detected, while yolk sac tumors secrete $\alpha$-fetoprotein (AFP). Elevation of AFP levels, combined with characteristic magnetic resonance imaging (MRI) results, is diagnostic for NGGCT (8). In pure germinomas, AFP is never elevated, but certain germinomas may secrete $\beta-\mathrm{HCG}$ at levels seldom $>50$ IU/1 (9).

Due to of the rarity of this disease, reports of adult intracranial GCTs are scarce. The clinical features of GCT in adult patients are likely to be different from those in children. The present study described a rare case of $\beta$-hCG secreting primary intracranial GCT in a 38 year-old man involving the pineal gland, the stalk and posterior pituitary gland, the right basal ganglion, the hypothalamus, the corpus callosum and posterior hippocampus, with presentations of hypogonadotropic hypergonadism, panhypopituitarism, diabetes insipidus (DI) and psychological symptoms. 


\section{Case report}

The present study was approved by the Ethics Committee of Taipei City Hospital and written informed consent was obtained from the patient.

A 38-year-old male patient with alcoholic liver disease and chronic hepatitis B presented with general weakness and body weight loss of $10 \mathrm{~kg}$ in 2 years was admitted to Department of Medicine, Taipei City Hospital Ren-Ai Branch (Taipei, Taiwan) in March 2012. The patient suffered poor work performance, emotional instability, lack of energy, insomnia and decreased libido for 1 year. Polydipsia was also noted during this period.

A physical examination revealed a man of chronically-ill appearance with normal development of the testis, pubic hair and axillary hair without gynecomastia. The daily urine output of the patient was $>10,000 \mathrm{ml}$, which did not decrease following fluid restriction. Low urine density and mild hypernatremia suggested a diagnosis of DI, but it was not possible to perform a water deprivation test due to the agitated mood and behavior of the patient.

Laboratory evaluation of an 8AM sample on admission revealed the presence of adrenocorticotropic hormone [14.3 pg/ml (10-65 pg/ml)], cortisol [1.34 $\mu \mathrm{g} / \mathrm{dl}(5-14 \mu \mathrm{g} / \mathrm{dl})]$, thyroxine stimulating hormone $[0.12 \mu \mathrm{IU} / \mathrm{ml}(0.1-4.5 \mu \mathrm{IU} / \mathrm{ml})]$, free thyroxine $[0.68 \mathrm{ng} / \mathrm{dl}(0.7-1.75 \mathrm{ng} / \mathrm{dl})]$, follicle-stimulating hormone $(\mathrm{FSH} ;<0.1 \mathrm{mIU} / \mathrm{ml})$, luteinizing hormone $(\mathrm{LH}$; $0.17 \mathrm{mIU} / \mathrm{ml})$, testosterone $[1,480 \mathrm{ng} / \mathrm{dl}(70-620 \mathrm{ng} / \mathrm{dl})]$, prolactin $(56 \mathrm{ng} / \mathrm{ml})$, insulin-like growth factor-1 $[52.4 \mathrm{ng} / \mathrm{ml}$ $(109.0-284.0 \mathrm{ng} / \mathrm{ml})]$. Panhypopituitarism-associated central hypoadrenalism, central hypothyroidism and growth hormone deficiency were also noted. However, it was not possible to explain the hypogonadotropic hypergonadism.

A brain MRI scan revealed the presence of a heterogeneous lesion involved in the right basal ganglion, hypothalamus, and the extension to the corpus callosum and to the posterior hippocampus. The pineal gland, stalk and posterior pituitary gland were also involved (Fig 1). A lumber puncture was performed and CSF cytology revealed no malignant cells, but CSF $\beta$-hCG levels of $1,936 \mathrm{IU} / 1$ and AFP levels $<0.24 \mathrm{ng} / \mathrm{ml}$. The serum AFP level was $3.28 \mathrm{ng} / \mathrm{ml}$, and the $\beta$-hCG level was $178 \mathrm{IU} / \mathrm{l}$, with a CSF:serum $\beta$-hCG ratio $>2: 1$. Neck to pelvis computed tomography excluded the presence of metastatic lesions. It was not possible to obtain a pathological diagnosis due to the deep location of the tumors. However, a $\beta$-hCG secreting suprasella GCT was suspected due to imaging and tumor markers.

The patient underwent hormone replacement therapy consisting of $10 \mathrm{mcg}$ of minirin nasal spray, $100 \mu \mathrm{g}$ thyroxin and $5 \mathrm{mg}$ prednisolone per day from March 2012. First cycle of chemotherapy with BEP regimen $(30 \mathrm{mg}$ bleomycin in $0.9 \%$ saline as a total of $100 \mathrm{ml}$ on day 1,8 and $15 ; 100 \mathrm{mg} / \mathrm{m}^{2}$ etoposide per day for days $1-5$ as a 4 -h infusion in $0.9 \%$ sodium chloride in a total of $500 \mathrm{ml} ; 20 \mathrm{mg} / \mathrm{m}^{2}$ cisplatin per day for days $1-5$ as a 4 -h infusion with $0.9 \%$ sodium chloride in a total of $500 \mathrm{ml}$ ) was performed at Taipei City Hospital Ren-Ai Branch (Taipei, Taiwan). After 2 cycles of this chemotherapy from April to May 2012, the serum $\beta$-hCG levels of the patient decreased to $22.2 \mathrm{IU} / 1$ in May 2012. Intensity modulation radiation therapy was performed with $25.2 \mathrm{~Gy}$ to the whole ventricle and a radiation treatment boost to administer an overall total of $45 \mathrm{~Gy}$ to the GCT site from June to August 2012.
Following 6 cycles of chemotherapy and radiotherapy, a brain MRI scan revealed that the tumors markedly decreased in size (Fig 2). The serum $\beta$-hCG levels of the patient fell to $0.3 \mathrm{IU} / 1$ and hyperandrogenemia subsided, with testosterone levels recorded as $84 \mathrm{ng} / \mathrm{dl}$. However, the psychological symptoms of the patient, including irritability and emotional instability, only improved a little.

\section{Discussion}

$\beta$-hCG-secreting intracranial GCTs are primarily diagnosed by young adolescence. The majority of patients are diagnosed with presentation of precocious puberty due to excess testosterone, which permits physicians to detect the disease earlier (10). Reports of adult $\beta$-hCG secreting intracranial GCTs are rare, the clinical characteristics are likely to be nonspecific and differ from those observed in children. To the best of our knowledge, there are no prior published case reports concerning patients older than 30 years that have been diagnosed with $\beta$-hCG secreting intracranial GCTs. Therefore, the present study will be the first to report a patient with this later age of onset.

GCTs are a varied group of neoplasms derived from the primordial germ cells, and they are classified as extragonadal, if there is no evidence of a primary tumor in either the testes or the ovaries. In adults, intracranial GCTs are the most well-known extragonadal GCT. However, primary intracranial GCT are still rare, accounting for $2 \%$ of all primary intracranial neoplasms in the USA and Europe, and 3-10\% of brain tumors in children from Asian countries (1). Males are affected more than females, at a ratio of $2: 1$ to $3: 1$. The majority of patients $(60-70 \%)$ are $<20$ years old, and $53 \%$ of patients are between 10 and 19 years old at the point of diagnosis. The disease is rare in patients $>35$ years old (4).

Intracranial GCTs are heterogeneous with respect to histology, biological profile, response to treatment and secretion of AFP and $\beta$-HCG into the serum and/or CSF (11). For the majority of patients with presumed intracranial GCTs, clinical manifestation and neurological image results are not specific enough to provide a definitive diagnosis. Clinical presentation depends upon the size and the localization of the tumor. Intracranial GCTs may be situated over the pineal and suprasellar regions and spread along the neuroaxis, with $\sim 15 \%$ demonstrating the involvement of multiple sites (12). The majority of GCTs are located at the pineal region, followed by the suprasellar region (12). Patients with pineal germinoma may present with insomnia, but interference with pituitary function is rarely observed (13). Pineal tumors often manifest with symptoms of obstructive hydrocephalus (14) and Parinaud's syndrome, characterized by the paralysis of upward gaze and convergence, may occur in $50 \%$ of patients (15). Suprasellar tumors are often characterized as endocrinopathies due to the disruption of the hypothalamic-pituitary axis (16). Hypothalamic-pituitary dysfunction may include DI, delayed pubertal development, isolated growth hormone deficiency, hypogonadotropic hypogonadism and any aspect of hypopituitarism, including central hypothyroidism and adrenal insufficiency. DI is the most common and is often the first presentation. Ophthalmic abnormalities, including bilateral hemianopsia, may also develop due to chiasmic or optic nerve 


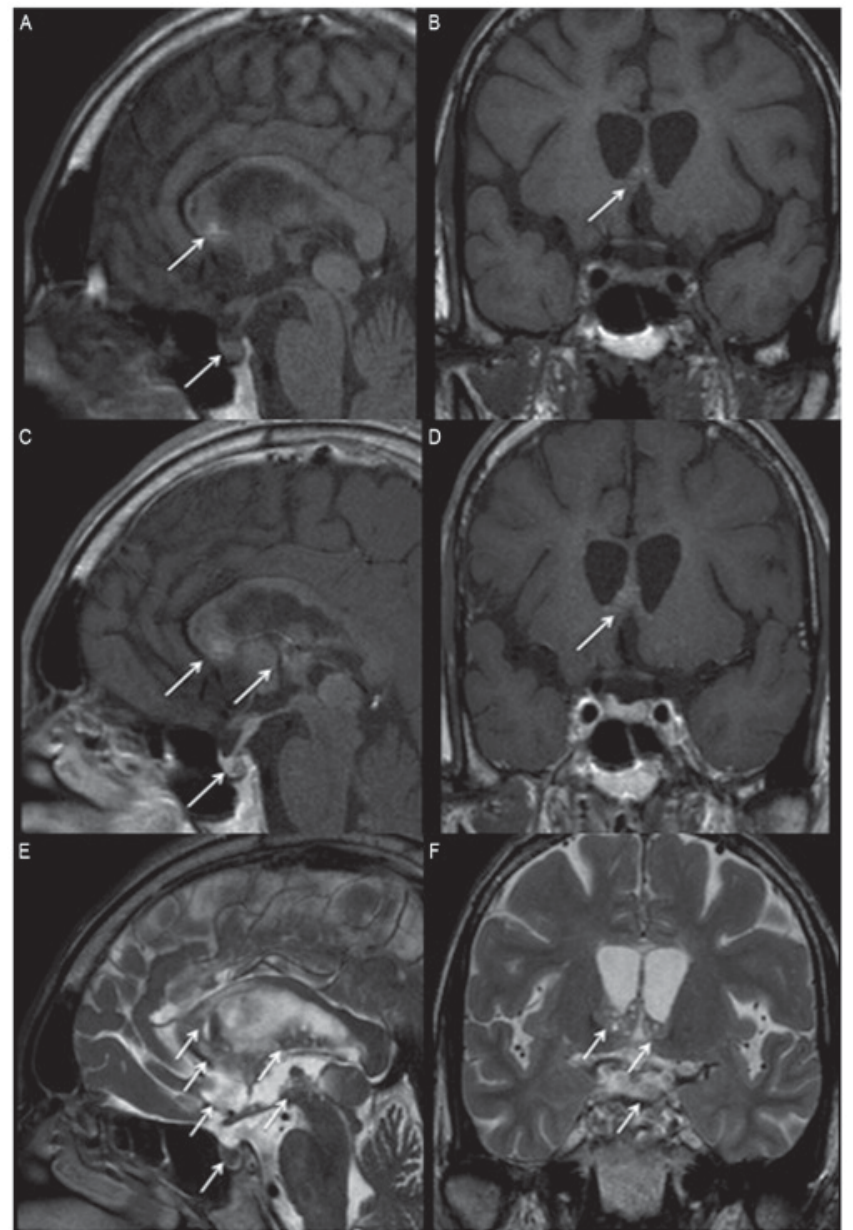

Figure 1. Magnetic resonance imaging of sella prior to treatment Heterogeneous lesions are indicated by arrows and are present in the basal ganglion, hypothalamus, corpus callosum, posterior hippocampus, pineal gland, stalk and posterior pituitary gland in (A) non-contrast sagittal, (B) coronal, (C) contrast sagittal and (D) coronal T1 weighted images, as well as (E) T2 weighted sagittal and (F) coronal images.

compression (13). Delays in diagnosis are common and may exceed 12 months, in particular when patients present with symptoms associated with endocrinopathy, and this results in higher incidences of disseminated disease.

Histologically, germinomas are the most common subtype of intracranial GCTs, accounting for $70-80 \%$ of all GCTs, and they are histologically identical to testicular seminoma and dysgerminoma of the ovary $(7,17)$. Non-germinomatous GCTs account for $20-30 \%$ of intracranial GCTs, including embryonal carcinoma, yolk sac tumors, choriocarcinoma and teratoma (7). Patients with pure germinoma may have mildly elevated $\beta$-hCG in contrast to the marked elevation of $\beta$-hCG observed in choriocarcinoma, but AFP is never elevated in germinoma. The latter is secreted by yolk sac tumors. When $\beta$-hCG is secreted by GCTs, it causes gonadotropin-independent hypergonadism with low LH/FSH and high testosterone due to the stimulating effect of $\beta$-hCG on the $\mathrm{LH}$ receptor in the testes. When this occurs in young male patients, which make up the majority of cases, precocious puberty will occur. In adult male patients, there are no reports of clinical features of androgen excess associated with $\beta$-hCG secreting intracranial GCTs. Fung et al (18) reported a 32-year old male with testicular seminoma with $\beta$-hCG secretion

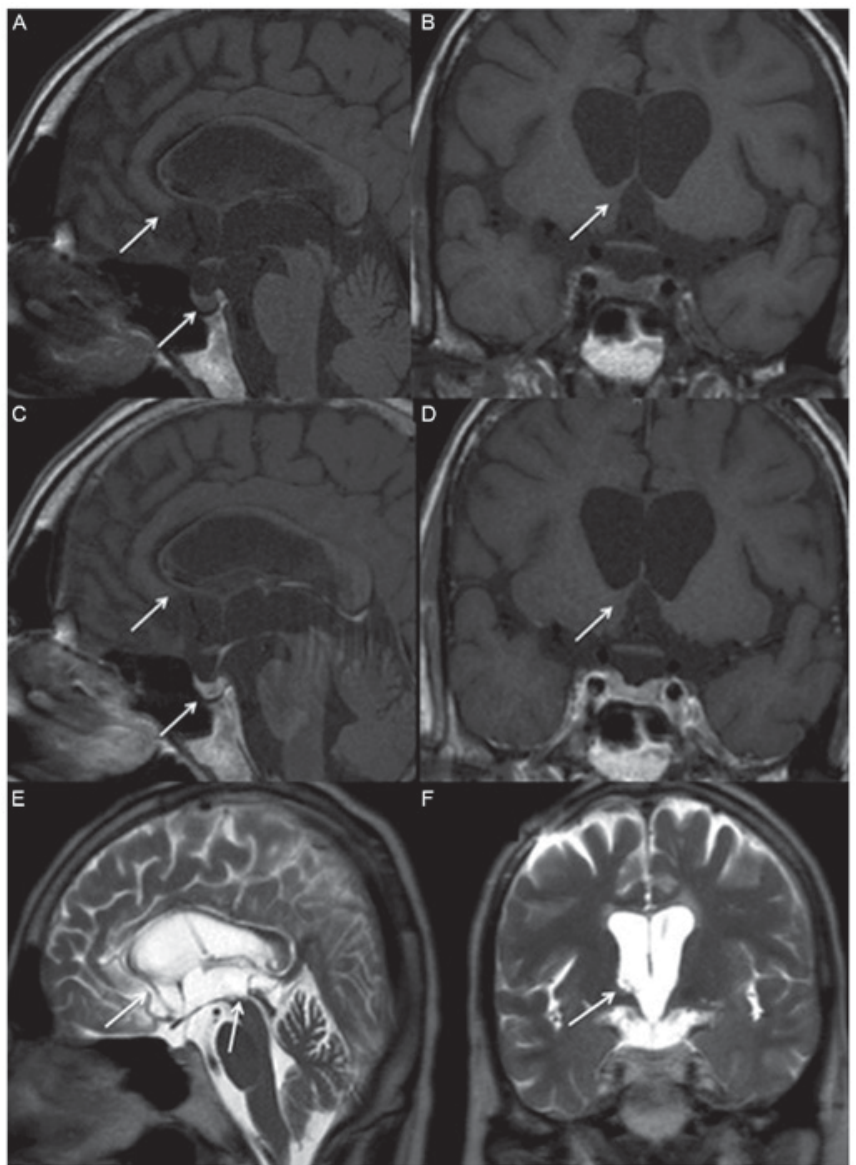

Figure 2. Magnetic resonance imaging of suprasella two years following treatment. The tumors over the basal ganglion, hypothalamus, corpus callosum, posterior hippocampus, pineal gland, stalk and posterior pituitary gland have disappeared, as indicated by arrows, in (A) non-contrast sagittal, (B) coronal, (C) contrast sagittal and (D) coronal T1 weighted images, as well as (E) T2 weighted sagittal and (F) coronal images.

and associated hyperandrogenism. The patient presented with worsening in acne and increased muscle bulk (18). Other case reports of testosterone excess by seminoma in testes or mediastinum shared clinical features with gynecomastia or male infertility in adult male patients (19-21).

The present study concerns a well-developed adult patient with two daughters. In contrast with the symptoms of hyperandrogenemia, the symptoms of the patient were decreased libido, motivation and vitality. The aggressive behavior and irritable mood exhibited by the patient were initially attributed to high testosterone levels, but these symptoms did not disappear when testosterone levels decreased. Structural damage to brain tumor tissue and late effects following radiotherapy may be the explanation. A debate remains concerning late neurocognitive dysfunction following radiotherapy. The neurocognitive function of the patient deteriorated to mirror child-like behavior, but improved half a year later. The previous symptoms, including fatigue and weakness, improved following hormone replacement with eltroxin and prednisolone.

Radiological diagnosis of intracranial GCT with MRI or computed tomography is a useful tool, with MRI being the optimal modality. MRI demonstrates soft tissue masses with isointense or slightly hyperintense signals in T1 weighted images, which may be accompanied with calcification or cyst 
formation in T2 weighted images (22). Definitive diagnosis of GCT is performed through the histopathology approach: The majority of GCTs demonstrate immunohistochemical staining for placenta-like alkaline phophatase and c-Kit, otherwise known as CD117, which is an important mitogen for normal germ cells (11). Unfortunately, a biopsy is not possible for patients where the tumor location is inaccessible. CSF $\beta$-hCG assays reflect the intensity of intracranial $\beta$-hCG secretion and are more sensitive than serum $\beta$-hCG levels (23). A $\beta$-hCG concentration in CSF $>50 \mathrm{IU} / 1$ and a CSF/serum $\beta$-hCG ratio $\geq 2$ has been suggested to be an indicator of the presence of a CNS GCT (24), which was observed in the patient enrolled in the present study.

Intracranial GCTs are sensitive to chemotherapy and radiotherapy. Cranio-spinal irradiation or whole ventricular radiotherapy to a dose of 25-35 Gy followed by a primary tumor boost for a total dose of 45-50 Gy is associated with a superior outcome, with a 5-year survival rate of $80-99.5 \%$ in retrospective and prospective studies (25). Chemotherapy agents including cyclophosphamide, ifosfamide, etoposide, cisplatin, and carboplatin are also highly active in CNS GCTs (26). The brain MRI of the patient enrolled in the present study following treatment revealed that the tumors markedly decreased in size, and $\beta$-hCG levels were within normal range. The patient has maintained a stable disease status since August 2015 in Taipei City Hospital Ren-Ai Branch.

In conclusion, the incidence of adult $\beta$-hCG secreting intracranial GCT is low. Compared with the majority patients, who are diagnosed in early pubertal years upon presentation of precocious puberty, the symptoms in adult patients are primarily associated with tumor size and location, with pituitary hormone deficiency rather than symptoms associated with testosterone excess.

\section{References}

1. Echevarría ME, Fangusaro J and Goldman S: Pediatric central nervous system germ cell tumors: A review. Oncologist 13: 690-699, 2008.

2. Nakamura H, Makino K, Yano S and Kuratsu J; Kumamoto Brain Tumor Research Group: Epidemiological study of primary intracranial tumors: A regional survey in Kumamoto prefecture in southern Japan-20-year study. Int J Clin Oncol 16: 314-321, 2011.

3. Ostrom QT, Gittleman H, Liao P, Rouse C, Chen Y, Dowling J, Wolinsky Y, Kruchko C and Barnholtz-Sloan J: CBTRUS statistical report: Primary brain and central nervous system tumors diagnosed in the United States in 2007-2011. Neuro Oncol 16 (Suppl 4): iv1-iv63, 2014.

4. McCarthy BJ, Shibui S, Kayama T, Miyaoka E, Narita Y, Murakami M, Matsuda A, Matsuda T, Sobue T, Palis BE, et al: Primary CNS germ cell tumors in Japan and the United States: An analysis of 4 tumor registries. Neuro Oncol 14: 1194-1200, 2012.

5. Jennings MT, Gelman R and Hochberg F: Intracranial germ-cell tumors: Natural history and pathogenesis. J Neurosurg 63: 155-167, 1985.

6. Hoffman HJ, Otsubo H, Hendrick EB, Humphreys RP, Drake JM, Becker LE, Greenberg $M$ and Jenkin D: Intracranial germ-cell tumors in children. J Neurosurg 74: 545-551, 1991.

7. Louis DN, Ohgaki H, Wiestler OD, Cavenee WK, Burger PC, Jouvet A, Scheithauer BW and Kleihues P: The 2007 WHO classification of tumours of the central nervous system. Acta Neuropathol 114: 97-109, 2007.
8. Calaminus G, Bamberg M, Harms D, Jürgens H, Kortmann RD, Sörensen N, Wiestler OD and Göbel U: AFP/beta-HCG secreting CNS germ cell tumors: Long-term outcome with respect to initial symptoms and primary tumor resection. Results of the cooperative trial MAKEI 89. Neuropediatrics 36: 71-77, 2005.

9. Ogino H, Shibamoto Y, Takanaka T, Suzuki K, Ishihara S, Yamada T, Sugie C, Nomoto Y and Mimura M: CNS germinoma with elevated serum human chorionic gonadotropin level: Clinical characteristics and treatment outcome. Int J Radiat Oncol Biol Phys 62: 803-808, 2005.

10. Marshall GA, McMahon SK, Nicholls W, Pretorius CJ and Ungerer JP: Gonadotrophin-independent precocious puberty in an eight-year-old boy due to ectopic human chorionic gonadotrophin from the central nervous system. Ann Clin Biochem 47: 271-274, 2010.

11. Bromberg JE, Baumert BG, de Vos F, Gijtenbeek JM, Kurt E, Westermann AM and Wesseling P: Primary intracranial germ-cell tumors in adults: A practical review. J Neurooncol 113: 175-183, 2013.

12. Matsutani M, Sano K, Takakura K, Fujimaki T, Nakamura O, Funata $\mathrm{N}$ and Seto T: Primary intracranial germ cell tumors: A clinical analysis of 153 histologically verified cases. J Neurosurg 86: 446-455, 1997.

13. Loto MG, Danilowicz K, González Abbati S, Torino R and Misiunas A: Germinoma with involvement of midline and off-midline intracranial structures. Case Rep Endocrinol 2014: 936937, 2014.

14. Sethi RV, Marino R, Niemierko A, Tarbell NJ, Yock TI and MacDonald SM: Delayed diagnosis in children with intracranial germ cell tumors. J Pediatr 163: 1448-1453, 2013.

15. Chao CK, Lee ST, Lin FJ, Tang SG and Leung WM: A multivariate analysis of prognostic factors in management of pineal tumor. Int J Radiat Oncol Biol Phys 27: 1185-1191, 1993.

16. Crawford JR, Santi MR, Vezina G, Myseros JS, Keating RF, LaFond DA, Rood BR, MacDonald TJ and Packer RJ: CNS germ cell tumor (CNSGCT) of childhood: Presentation and delayed diagnosis. Neurology 68: 1668-1673, 2007.

17. Kamoshima Y and Sawamura Y: Update on current standard treatments in central nervous system germ cell tumors. Curr Opin Neurol 23: 571-575, 2010

18. Fung LC, Honey RJ and Gardiner GW: Testicular seminoma presenting with features of androgen excess. Urology 44: 927-929, 1994

19. Nagi DK, Jones WG and Belchetz PE: Gynecomastia caused by a primary mediastinal seminoma. Clin Endocrinol (Oxf) 40: 545-549, 1994

20. Lefebvre H, Laquerriere A, Cleret JM and Kuhn JM: A hCG-secreting testicular seminoma revealed by male infertility: Mechanism of hCG-evoked endocrine disturbances. Andrologia 25: 283-287, 1993.

21. Djaladat H, Nichols C and Daneshmand S: Androgen-producing testicular germ cell tumors. J Clin Oncol 29: e634-e635, 2011.

22. Kanagaki M, Miki Y, Takahashi JA, Shibamoto Y, Takahashi T, Ueba T, Hashimoto N and Konishi J: MRI and CT findings of neurohypophyseal germinoma. Eur J Radiol 49: 204-211, 2004.

23. Tian C, Shi Q, Pu C, Huang X, Yu S, Zhang J, Huang D, Wang X and Liu R: Re-evaluation of the significance of cerebrospinal fluid human chorionic gonadotropin in detecting intracranial ectopic germinomas. J Clin Neurosci 18: 223-226, 2011.

24. Katagami H, Hashida S, Yamaguchi H, Yazawa S, Nakano S and Wakisaka S: Diagnosis and course of treatment of CNS germinoma assessed by highly sensitive immune complex transfer enzyme immunoassay to detect HCG. Horumon to Rinsho 51: 196-206, 2003.

25. Kortmann RD: Current concepts and future strategies in the management of intracranial germinoma. Expert Rev Anticancer Ther 14: 105-119, 2014.

26. Lim DH, Yoo KH, Lee NH, Lee SH, Sung KW, Koo HH, Kim JH, Suh YL, Joung YS and Shin HJ: Intensive chemotherapy followed by reduced-dose radiotherapy for biopsy-proven CNS germinoma with elevated beta-human chorionic gonadotropin. J Neurooncol 117: 279-285, 2014. 